\title{
Effects of Non-Thermal Argon Plasma Produced at Atmospheric Pressure on the Optical Properties of CdO Thin Films
}

Hamid H.Murbat

\author{
Nisreen KH. Abdalameer* \\ Farah abdulameer
}

Alaa Kh.Brrd

\author{
Received 10/1/2017, Accepted 21/5/2018, Published 4/6/2018
}

This work is licensed under a Creative Commons Attribution 4.0 International License.

\begin{abstract}
:
In this paper the effect of nonthermal atmospheric argon plasma on the optical properties of the cadmium oxide $\mathrm{CdO}$ thin films prepared by chemical spray pyrolysis was studied. The prepared films were exposed to different time intervals $(0,5,10,15,20) \mathrm{min}$. For every sample, the transmittance, Absorbance, absorption coefficient, energy gap, extinction coefficient and dielectric constant were studied. It is found that the transmittance and the energy gap increased with exposure time, and absorption. Absorption coefficient, extinction coefficient, dielectric constant decreased with time of exposure to the argon plasma.
\end{abstract}

Keywords: Non thermal plasma, Cadmium oxide, Spray pyrolysis method, Optical properties.

\section{Introduction:}

\section{Non-thermal plasma}

Plasma is the fourth state of matter (in addition to the three known states of solid, liquid, gaseous); the plasma is classified according to its temperature to two main types: high temperature plasma or nuclear fusion plasma and low temperature plasma or so called plasma discharge. High temperatures are those in which all particles (electrons, ions and neutral particles) in the case of thermal equilibrium $\left(\mathrm{T}_{\mathrm{e}} \approx \mathrm{T}_{\mathrm{i}} \approx \mathrm{T}_{\mathrm{n}}\right)$. Plasma low temperatures are divided into two parts: the thermal plasma, whose components are in the case of local equilibrium and non-thermal plasma, where the temperature of the electrons is much higher than the temperature of the rest of the items $\left(\mathrm{T}_{\mathrm{e}} \gg \mathrm{T}_{\mathrm{i}} \approx \mathrm{T}_{\mathrm{n}}\right)$ (1). Cold plasma at atmospheric pressure has wide applications in industrial and scientific fields including: environmental applications (2), biodegradation (3), nanotechnology applications (4) and materials treatment (5).

At present, various sources of non-thermal plasma production have been developed at normal atmospheric pressure for use in surface treatment (6). This type of plasma has many advantages when used in surface treatment compared with other methods of treatment such as the use of chemicals or the use of plasma produced in low pressure, These include reduced maintenance and operating costs, reduced processing time and no waste or toxic substances. Intensive studies were conducted Department of Physics, College of Science for Women, University of Baghdad, Iraq

"Correspondence: physical2017@yahoo.com on the effect of non-thermal plasma at atmospheric pressure on polymers(7), textiles(8) or plastic surfaces(9), when there are necessities for superficial modifications to overcome some technology issues in materials, such as reducing wetness or moisture to the surface or to increase adhesion. And in comparison with the number of studies on the effect of non-thermal plasma on polymerase, it has been studied for metal surfaces but less and still needs a lot of work in this subject (10). A large number of researches has been published in the use of plasma to treat metal surfaces, whether cleaned or activated (11). This means that plasma is used to prepare the surface before it is ready for other processes such as paint, drawing or bonding.

In this paper, the effects of non-thermal Argon plasma produced at normal atmospheric pressure on the optical properties of $\mathrm{CdO}$ thin films will be studied.

\section{Cadmium Oxide (CdO)}

Cadmium oxide $(\mathrm{CdO})$ has a high electrical conductivity and high optical transmittance with a moderate refractive index in the visible region of the solar spectrum $(12,13)$. CdO thin films have been widely used as transparent conducting oxide thin films due to its low resistivity and high optical transmittance(14); its optical band gab is about $2.16 \mathrm{eV}$ at room temperature depending on the kind of technique used and the preparation condition of the method used(15). The combination of high transparency in the visible range of the 
electromagnetic spectrum, high electrical conductivity, and high carrier concentration, these properties make $\mathrm{CdO}$ thin films very useful for many applications such as solar cell, phototransistor, diodes, gas sensors, heat mirror, antireflection coatings, transparent electrodes, photodiodes, etc. (16).

In recent years, it has been found various techniques that were used to prepare $\mathrm{CdO}$ thin films such as Thermal Evaporation in Vacuum Deposition. (TEVD), Sputtering technique, Chemical Vapor Deposition. (CVD), Pulse Laser Deposition. (PLD), Thermal Pyrolysis Deposition. (TPD). (17) The optoelectronic semiconductor material cadmium oxide has been extensively studied as epitaxial and polycrystalline thin films prepared by different techniques because of its unique optoelectronic and other properties with a hope of exploring potentialities for fabrication of new scientific and technological devices(18).

In this work, was studied the effect of nonthermal argon plasma produced at normal atmospheric pressure on the optical properties of $\mathrm{CdO}$ thin films that are prepared by chemical spray pyrolysis.

\section{Materials and Methods: \\ Preparation of thin films}

Transparent and conducting $\mathrm{CdO}$ thin films were deposited on glass substrates by using spray pyrolysis method. Cadmium acetate $\left(\mathrm{Cd}\left(\mathrm{CH}_{3} \mathrm{COO}\right)_{2} \cdot 2 \mathrm{H}_{2} \mathrm{O}\right)$ was used as a source material of $\mathrm{Cd}$ with concentration $\operatorname{about}(0.1 \mathrm{M})$ dissolving in $50 \mathrm{ml}$ re-distilled water, the microscope glass substrate after subjected to the cleaning process were placed on hot plate until it reaches $350 \dot{\mathrm{C}}$. The optimized deposition parameters such as spray time $(5 \mathrm{sec})$, substrate spray nozzle distance $(29 \mathrm{~cm})$, spray interval $(55 \mathrm{~s})$ and carrier gas pressure (compressed air $10^{5} \mathrm{Nm}^{-2}$ )

\section{Plasma jet system}

The plasma jet that was used in our experiment is shown in Fig.1 It consists of stainless steel tube with dimensions (20)mm length and inner diameter (3)mm; this tube was used as guide for argon gas and connect to the high voltage power supply. Another Pyrex tube with (150) mm length and inner diameter (7) $\mathrm{mm}$ serves as a shielding for the stainless steel tube, the second electrode of power supply was connected to the sheet of cupper with (10)mm width was putted at the outer end of the glass tube, the insulator of silicon was put over the external cupper electrode, so as to prevent direct discharge occurred.

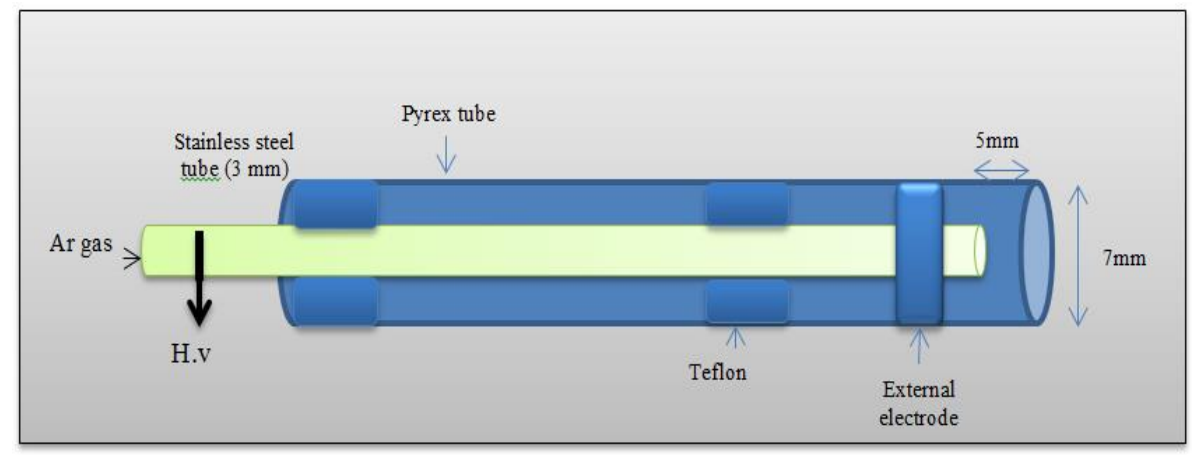

Figure 1. Schematic design for non thermal plasma needle

Argon gas was used to feed the system with flow rate of $3(1 / \mathrm{min})$ and a high voltage power supply with a ma voltage of $25 \mathrm{kV}$ and a frequency of $30 \mathrm{kHz}$. The voltage used in this work, has been set at $1.5 \mathrm{kV}$ and $22 \mathrm{kHz}$. Fig. 2 shows a photography of the plasma system that was used in thin film treatment.

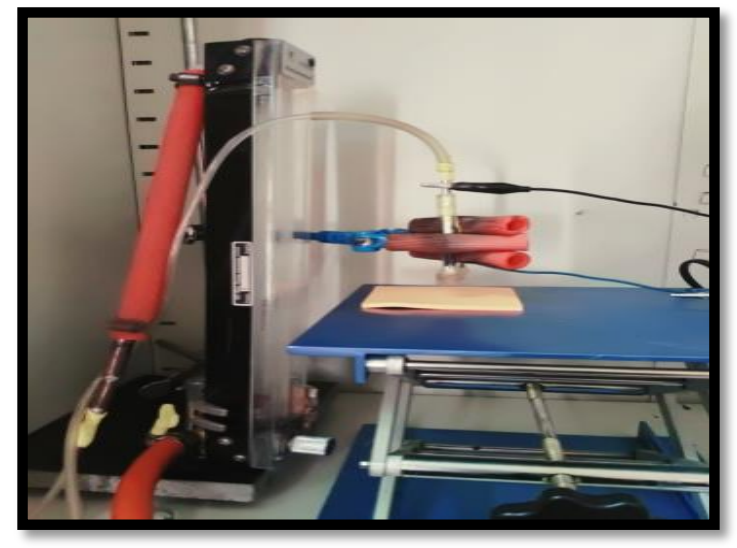

Figure 2. Illustrate a photography of the argon plasma jet system used the thin film treatment 


\section{Results and Discussion: Transmittance}

Figure 3 shows the spectrum of transmittance in the region of the spectrum (4001100) $\mathrm{nm}$ of the cadmium oxide film exposed to the Argon plasma for different time intervals $(0,5,10$, $15,20) \mathrm{min}$.

It was noted from the figure that the maximum transmissions value reaches $80 \%$, and for a given value of the wavelength the transmissions increases with the increased exposure time of the plasma.

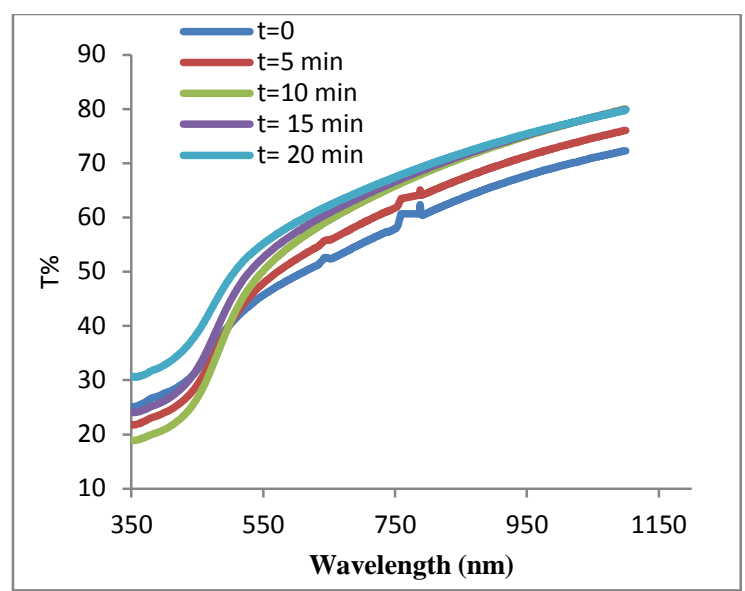

Figure 3. Shows spectrum of transmissions $\mathbf{T}$ as a function of wavelength of the cadmium oxide film exposed to the Argon plasma for different times intervals $(0,5,10,15,20) \mathrm{min}$.

\section{Absorbance}

Figure 4 shows the spectrum of absorption 'A' of the cadmium oxide film exposed to the Argon plasma for different times intervals $(0,5,10,15,20)$ min as a function of wavelength From the Figure, it can be shown that the absorption at a given wavelength decreases with increasing exposure time.

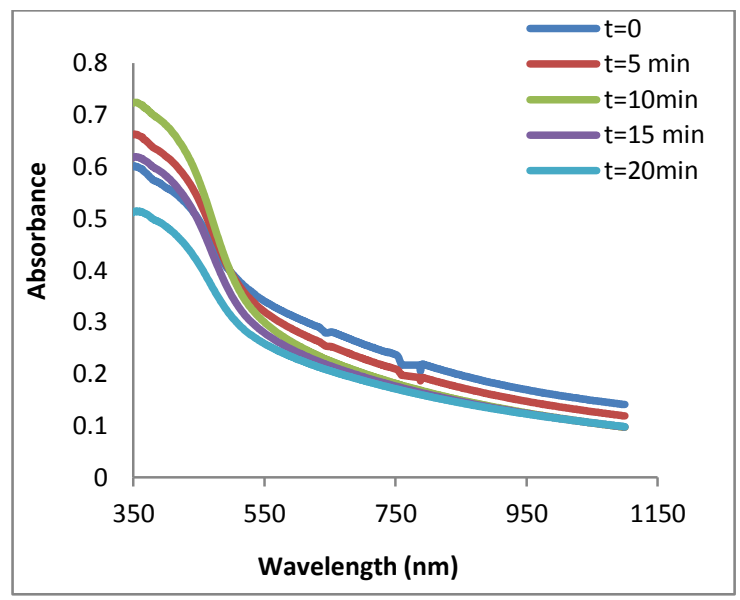

Figure 4. Absorption $A$ as a function of wavelength of the cadmium oxide film exposed to the Argon plasma for different times intervals (0, $5,10,15,20$ ) min.

Absorption coefficient

The absorption coefficient $\boldsymbol{\alpha}$ is calculated using the following Lambert formula (19):

$$
\alpha=\frac{2.303 A}{t}
$$

Where $\alpha$ is the absorption coefficient, A is the absorption and $t$ is thickness of the film.

Figure 5 shows the absorption coefficient as a function of wavelength in the region of the spectrum (400-1100) nm cadmium oxide film exposed to the Argon plasma for different time intervals $(0,5,10,15,20) \mathrm{min}$. It was noted from the figure that the absorption coefficient decreases with increasing wavelength, also at a given wavelength the absorption coefficient decreases with increasing exposure time.

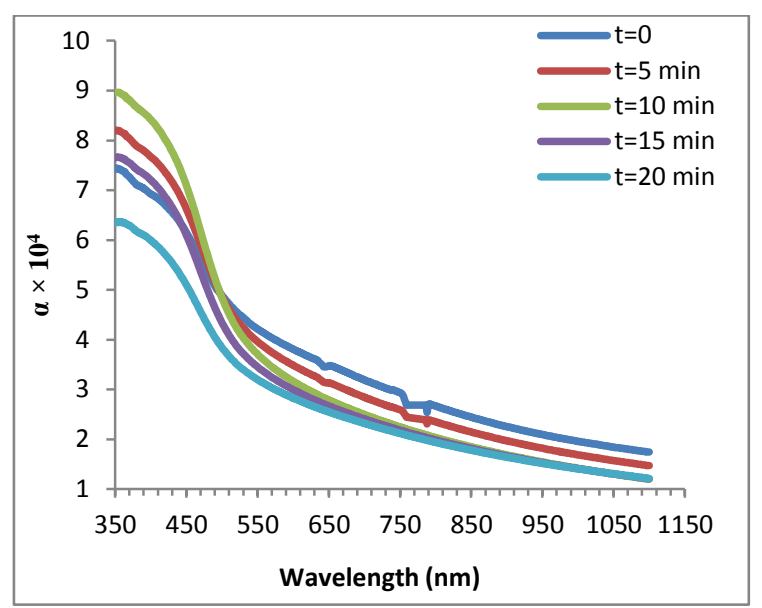

Figure 5. Absorption coefficient as a function of wavelength of the cadmium oxide film exposed to the Argon plasma for different times $(0,5,10,15$, 20) min.

\section{Energy gap}

The coefficient of absorption is given according to the Tauc 's relation as follows (20):

$$
\alpha \mathrm{hv}=B\left(\mathrm{hv}-E_{g}\right)^{m}
$$

where $\mathrm{B}$ is a constant; its value varies depending on the transitions, $E_{g}$ is the energy gap, hu is the photon energy, $\mathrm{m}$ is a constant that has value $1 / 2$ for direct allowed transmission for semiconductors (17). By plotting $(\alpha \mathrm{hv})^{2}$ against photon energy hu, when extending the straight part of the resulting curve to cut the hv axis at point $(\alpha \mathrm{hv})^{2}=0$, the intersection point represents the energy gap $E_{g}$.

Figure (4) shows the relationship between $(\alpha \mathrm{hv})^{2}$ as a function of photon energy for cadmium oxide films exposed for non-thermal Argon plasma for different time intervals $(0,5,10,15,20) \mathrm{min}$. The energy gap for each curve was calculated as $(2.206,2.2687,2.312,2.30,2.28) \mathrm{eV}$, respectively. 

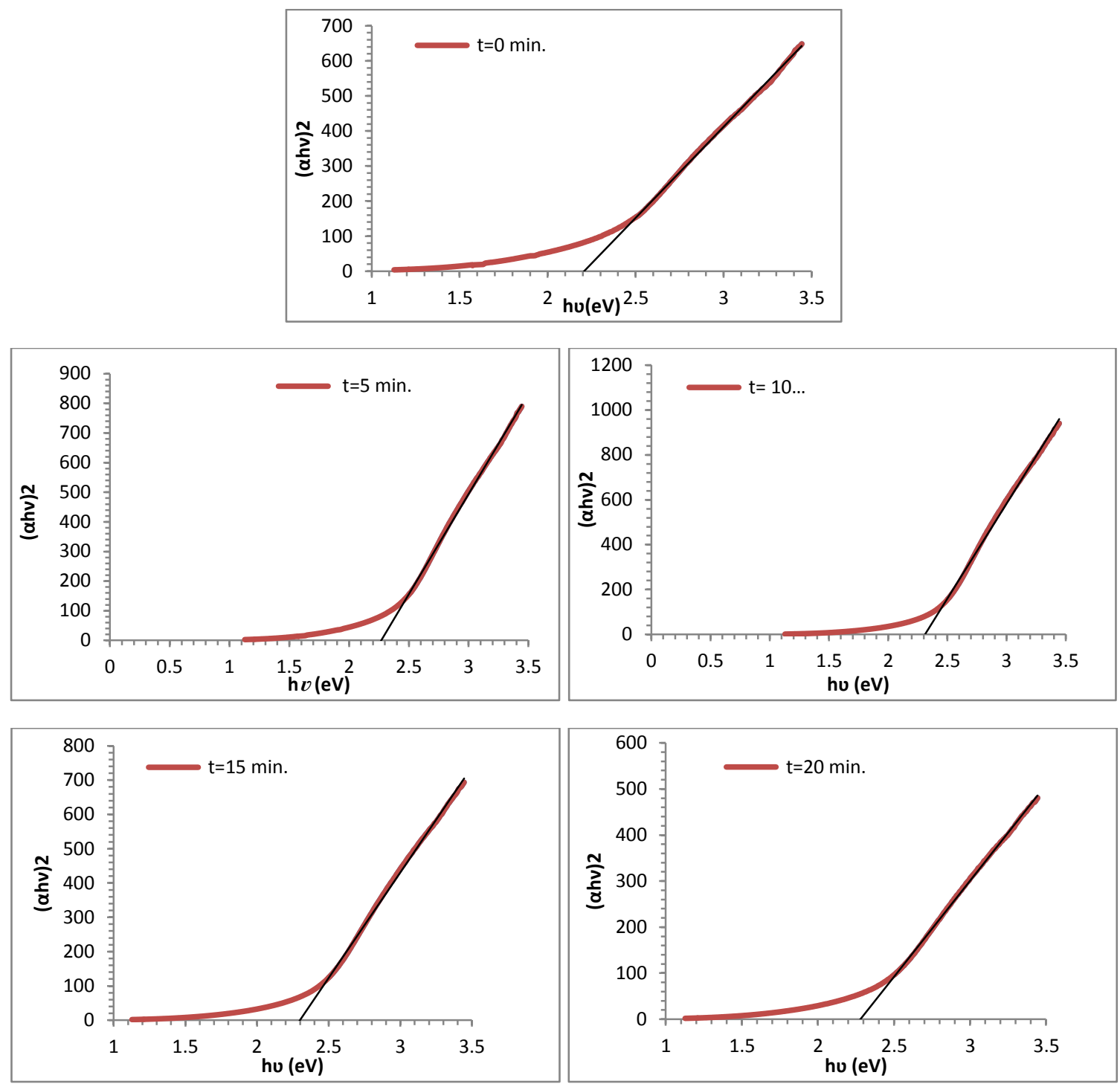

Figure 6. Energy gap as a function of photon energy of the cadmium oxide film exposed to the Argon plasma for different times interval $(0,5,10,15,20) \mathrm{min}$.

\section{Extinction Coefficient}

The Extinction coefficient ,K, of the prepared films is calculated by the following relation (20):

$$
K=\frac{\alpha \lambda}{4 \pi}
$$

Where as $\lambda$ the wavelength for incident photon.

Figure (7) shows the graph of extinction coefficient as a function of wavelength for cadmium oxide films exposed for non-thermal argon plasma for different time $(0,5,10,15,20) \mathrm{min}$. It shows the fact that when the wavelength was fixed, the Extinction coefficient decreased with an increase in the exposure time of the plasma.

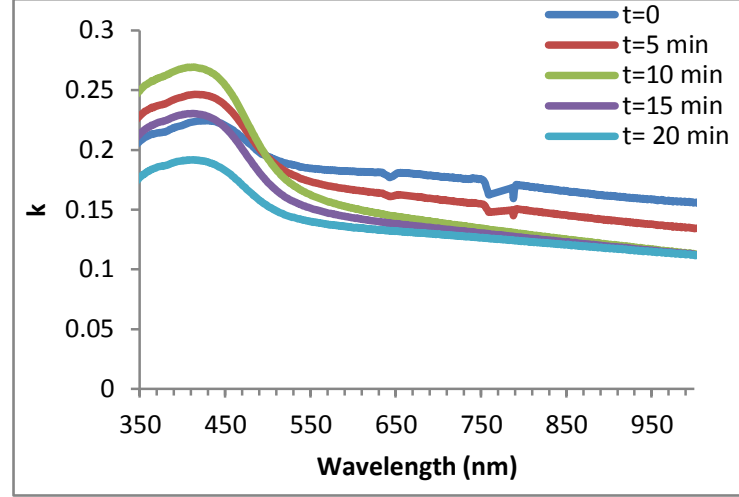

Figure 7. Extinction coefficient as a function of wavelength of the cadmium oxide film exposed to the Arcon plasma for different times $(0,5,10,15$, 20) min.

\section{Dielectric constant}

The values of the dielectric, $\boldsymbol{\varepsilon}$, constant are complex values that depend on a real $\varepsilon_{r}$ and imaginary part $\varepsilon_{i}$, as follows $(21,22)$ : 


$$
\text { where } \quad \begin{aligned}
\epsilon & =\varepsilon_{r}-i \varepsilon_{i} \\
\varepsilon_{r} & =n^{2}-K^{2} \\
\varepsilon_{i} & =2 n K
\end{aligned}
$$

Figure (8) shows the real and imaginary part of the dielectric constant, as a function of wavelength for cadmium oxide films exposed for non-thermal Argon plasma for different times $(0,5$, $10,15,20) \mathrm{min}$.

It is observed from the real and imaginary curves that the peaks of the curve creeps towards the long wavelengths by increasing the exposure time. Also, it is observed that for given value of the wavelength, the value of real and imaginary decreases with increasing the exposure time.
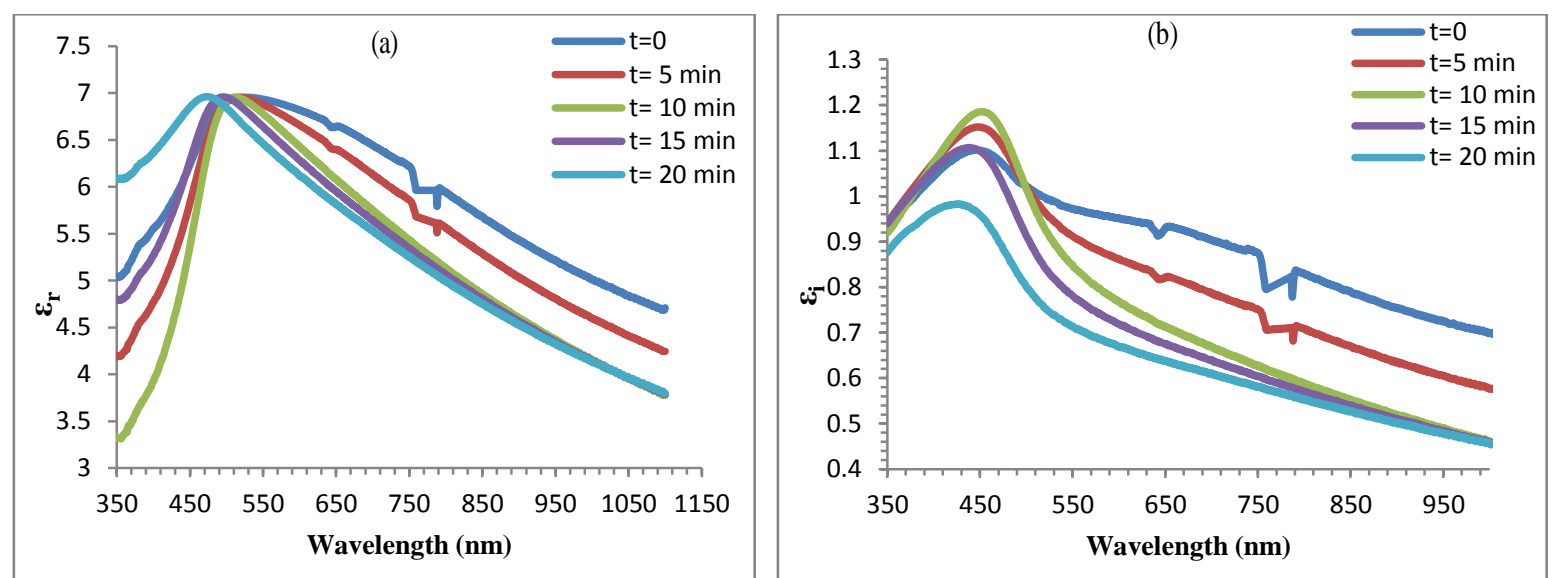

Figure 8. The Dielectric constant ( $($ ) (real part (a) and imaginary part (b))as a function of wavelength of the cadmium oxide film exposed to the Argon plasma for different times $(0,5,10,15,20) \mathrm{min}$.

\section{Conclusion:}

In this work, it was found that the transmissions $\mathrm{T}$ and Energy gap $E_{g}$ increases with increasing the time of exposure while absorption $\mathrm{A}$, absorption coefficient $\alpha$, extinction coefficient $\mathrm{K}$ and the real and imaginary part of the Dielectric constant decreased with increasing the time of exposure.

\section{Conflicts of Interest: None.}

\section{References:}

1. Vijay N, Ashok K, Dwivedi HK. Atmospheric nonthermal plasma source. Int. J. of Eng. 2008; 2(1): 5368.

2. Sabah N, Alyaa H, Nisreen Kh, Farah W. Studying the effect of cold plasma on the blood using digital image processing and image texture analysis. IEEE. 2016; SCOPES.

3. Kroesen MG, Morfill G, Nosenko T, Shimizu T, Van DJ, Zimmermann JL. Plasma medicine: an introductory review. New J Phys. 2009; 11:115012.

4. Ostrikov K. Control of energy and matter at nanoscales: Challenges and opportunities for plasma nanoscience in a sustainability age. J phys D Appl Phys. 2011;44: 174003.
5. Cao Z, Walsh JL, Kong MG. Atmospheric plasma jet array in parallel electric and gas flow fields for three dimensional surface treatment.Appl Phys. Lett. 2009; 94: 021501.

6. Vadym P, Atmospheric Pressure Plasma Jet in Ar and $\mathrm{O}_{2} /$ Ar Mixtures: Properties and High Performance for Surface Cleaning. journal Surf Eng. Mater Adv. Technol., 2013;3: 138-145.

7. Desmet T, Morent R., Geyter ND, Leys C, Schacht E, Dubruel P, Nonthermal plasma technology as a versatile strategy for polymeric biomaterials surface modification: a review. Biomacromolecules J. 2009;10(9):2351-2378.

8. Morent R, Geyter ND, Verschuren J, Clerck KD, Kiekens P, Leys C. Non-thermal plasma treatment of textiles. Surf \& Coat Technol. 2008; 202( 14):34273449.

9. Shenton MJ, Stevents GC. Liquid Metal Based Test Structures and Reconfigurable Microfluidic Microwave Devices and Antennas. J phys D Appl Phys. 2001; 34( 18):2761-2768.

10. Yamamoto T, Yoshiaki A, Kuroki T, Okubo M. Preparation of PTFE Film With Adhesive Surface Treated by Atmospheric-Pressure Nonthermal Plasma Graft Polymerization. IEEE Industry Applications Society . 2004; 40( 5):1220-1225.

11. Strohmeier BR. Effect of Surface Preparation and Thermoplastic Adhesive Structure on the Adhesion Behavior of Peek/Graphite Composites J Adhes Sci Technol. 1992; 6( 6):703-718.

12. Ubale AU, Wadnerkar SS, Sononeand PN, Tayade GD. Study of structural optical and electrical properties of $\mathrm{CdO}$ thin film. Archives of Physics Research. 2014; 5 (6):43-48. 
13. Zain AM, Ahmed TH, Yasmeen ZD. Studying The Optical Properties of $\mathrm{CdO}$ and $\mathrm{CdO}$ : Bi Thin Films. Baghdad Sci. J. 2016; 13(3).

14. Nadir FH, Buthainah AA, Eman SN. Influence of Irradiation on some Optical Properties of (CdO) Thin Films Prepared by Spray Pyrolysis. International Letters of Chemistry Physics and Astronomy. 2017; 74: $15-21$.

15. Ghazi YN, Waleed NR, Ali SF, Zenhe JR, Mohammed AS, Auday HA. Some optical properties of CdO thin films. Energy Procedia. 2013; $42-49$.

16. Ramiz AA. Structural Morphological and Optical Properties of CDO: Al Thin Films Prepared by Chemical Spray Pyrolysis Methode. IOSR J. Appl. Phys.2016; 8 : 06-15.

17. Barote MA. Optical and Electrical Properties of Spray Deposited Cdo Thin Films: Effect of Substrate Temperature. IJSR. 2013; 2 :10.
18. Samir AM, Alia AA, Ayad AS. The optical properties of aluminum doped $\mathrm{CdO}$ thin films prepared by vacuum thermal evaporation technique. Ibn alhaitham J. Pure \& Appl. Sci. 2014; (27) 3.

19. Tauc JC. In Optical Properties of Solid. NorthHolland Publishing, Amsterdam.1972; 279.

20. Nnabuchi MN.Solid state characterization of optimized manganes sulphide thin films and there possible applications in solar energy. PAC. J. Sci.Tecjno. 2006;7(1): 69-76.

21. Moss TS, Burrel GJ, Ellis B. Semiconductor OptoElectronics device. Wiley, New York. 1973.

22. Seham HS, Enas YA. Study the Effect of Irradiation on Structural and Optical Properties of $(\mathrm{CdO})$ Thin Films that Prepared by Spray Pyrolysis. Ibn AlHaitham J. Pure \& Appl. Sci. 2015; 28 (2).

\section{دراسة تاثير بلازما الاركون غير الحرارية المنتجة في الضغط الجوي الاعتيادي على الخواص البصرية CdO لاغشية اوكسيد الكادميوم}

فرح عبد الامير عبد الكريم
نسرين خليل عبد الامير

قسم الفيزياء، كلية العلوم للبنات، جامعه بغداد، بغداد ، العراق.

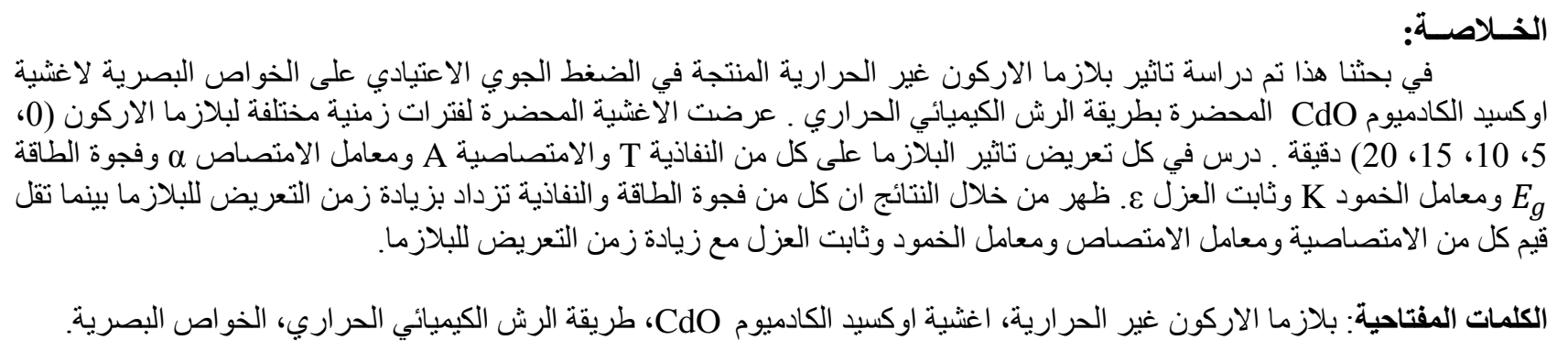

